\title{
Power and Use of Self: Mixed Emotions and Thoughts in Multidisciplinary Work
}

\author{
Christine Van Kooten \\ cvk146@mun.ca
}

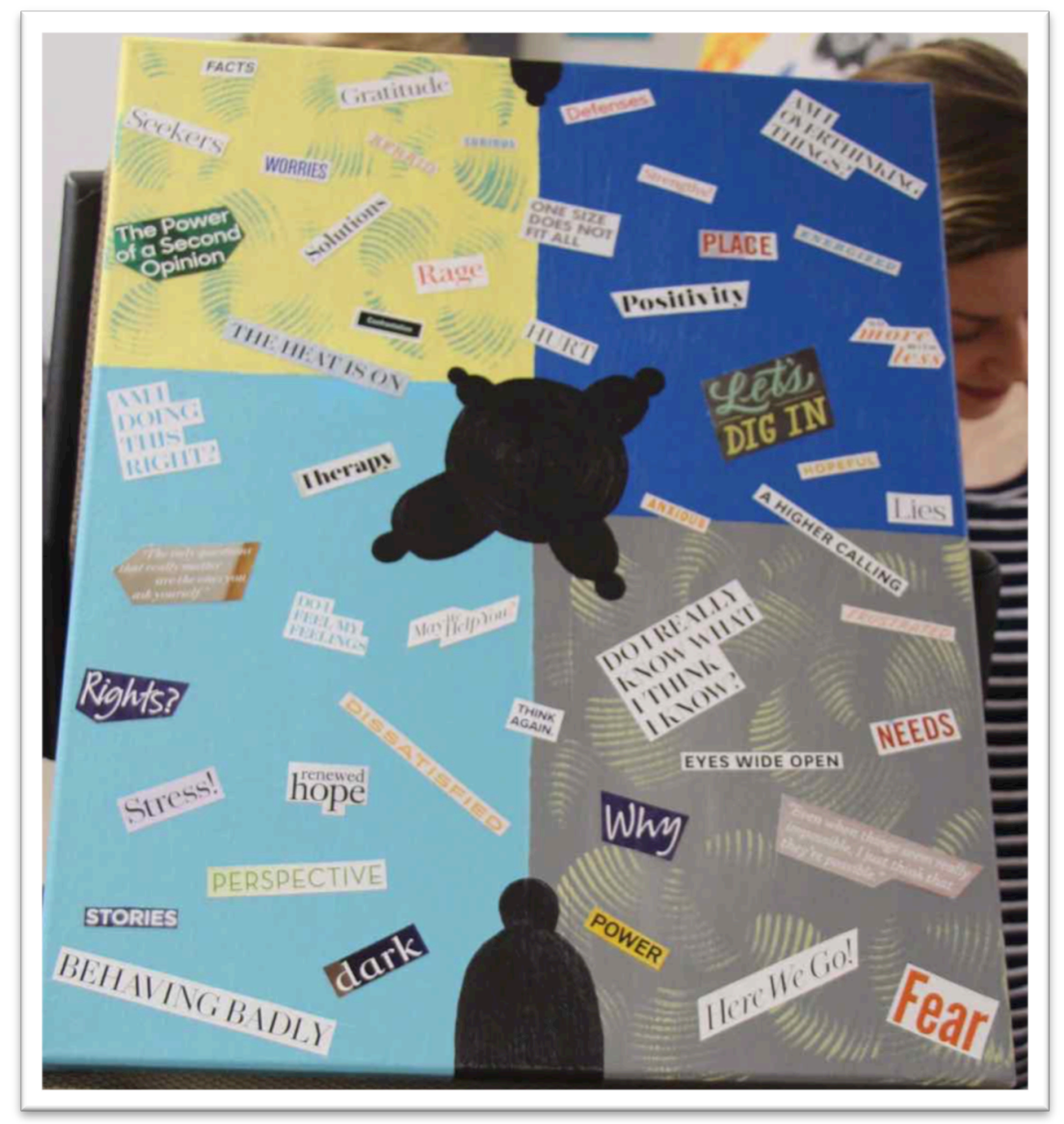

\section{- Acrylic and paper on canvas}

My painting depicts a multidisciplinary team meeting regarding a conflict that the team members were having with a client's psychiatrist who disagreed with their approach to a client's situation. The client is a man with an intellectual disability living in an adult residential program. He wishes to return to his rural hometown. However, this move has been attempted multiple times, but resulted in placement breakdown. The client is transfixed on the idea that he will be moving home someday, but to date, this has been deemed impossible. The team felt it was in the client's best interest that they explain to him that he will not be moving home, in the hope that he will begin to settle and become more integrated in the community. Although the psychiatrist agrees that the client cannot move home, she continues to tell him it will happen in the future. Quite understandably, this has impacted the team's efforts to support him with integrating into 
the community. The team is unsure what steps to take without the psychiatrist's agreement, and questions the psychiatrist's professional ethics. Therefore, a meeting was scheduled with the social workers' ethics committee, for which the team was meeting to prepare.

For my artistic piece, the colours grey and blue were chosen to represent neutrality and calmness. Black and yellow were chosen due to their strong presence with black representing defeat and despair, and yellow representing hope. The colours and words surrounding the meeting table represent the mix of negative/concerning and positive/hopeful thoughts and feelings among the team - including myself - about the conflict. The size differences among the people in the painting identifies the power differentials, specifically, who holds the most power over the client. Throughout the process of reflection, for the assignment, this theme recurred. At times, my lack of power and the client's lack of power are obvious. Power differentials also highlight the hierarchy that exists between specializations in interdisciplinary work. In the painting, two people are outside of the group. Although they were involved with the issue, they did not attend the meeting. The two missing people are, the psychiatrist, who holds the most power, and the client, who holds very little.

I realize that the most valuable tool I bring to the field is my use of self, and that reflective and reflexive practices allow for the development of greater awareness of the power differentials inherent in any group work. From the placement, I realize also, that professionals' approaches, values and perspectives can affect other professionals and have impacts on the people that we serve.

\section{Awareness and Use of Self - Reflection \& Reflexivity}

As a student coming into the meeting depicted in my art piece with fresh eyes and ears, I had the ability to step back from what I was being told and could examine the situation with less influence than the team members seemed to have on each other. Afterwards, I met with one of the people who was present at the meeting and involved in the conflict, in order to gather more background on the situation. It was evident that she was not fond of the psychiatrist or psychiatrists in general. She explained how the situation got to this point. It helped me to see where collaboration and communication may have gone wrong. But how does such a negative professional narrative affect our work? This reminded me of the importance, not only of reflective practice but as importantly, of reflexivity in practice. Fook (2012) describes reflective and reflexive practice as two ways of critically examining our own place within different contexts and the implications of our social positions, values, and personalities as they shape our perspectives and ultimately our actions. We spend a lot of time reflecting on ourselves, our beliefs, our values, and what influences us in the social work program, and for good reason, but I think sometimes we overlook the usefulness of reflexive practice as it pertains to others and our attempts to understand their stance. For example, it seems easier to reflect on my own perceptions, social position, values, etc., to analyze my decision-making processes, perspective and beliefs, but it is more challenging to try to understand someone else's approach or actions because I am not inside their head or living their life. However, if I consider the context surrounding their professional position, it helps me to try to understand them better and see why they do the things they do, in order for me to communicate more effectively, with them. Their context is different to mine. Many factors influence who we are and how we think. Howe (2009) explains that reflexivity is the "realization that as we observe and engage with other people, we 
affect them, and as they are affected by us, in turn they affect us, and so on in an evolving dynamic of interpersonal transactions" (p. 171). In the case presented, if the social work team continuously views the psychiatrist as an enemy for holding the most power, then we need to take some of that power. We could include the psychiatrist at the table, as someone who will share in the decision-making. We would not try to go over his/her head, only to have our efforts negated. If I consider the bigger picture and deconstruct what may be influencing the psychiatrist's actions, perhaps I can better understand how to approach a similar situation in my future professional work with a team. With the knowledge, training and the abilities to practice reflectivity and reflexivity, I may help to avoid such future conflicts. 


\section{References}

Fook, J. (2012). Social work: A critical approach to practice (2nd ed). London, UK: Sage Publications.

Howe, D. (2009). A brief introduction to social work theory. London, UK: Palgrave Macmillan. 